\title{
An Inveatigation of the Role of Water on Retrograde/Condensation Reactions and Enhanced Liquafartion Yields
}

\author{
Francis P. Miknis
}

July, 1992

Quarterly Progress Report for the Period April 1, 1982 - June 30, 1992

Work Performed Under DOE Contract, DE-AC22-91PC91043

\section{DISCLAIMER}

By

Western Research Institute

Laramie, Wyoming
This report was prepared as an account of wotk sponsored by an agency of the Unitod States Government. Neither the United States Government nor any agency theroof, nor any of their employees, makes any warranly, express or implied, or assumes any legal liability or responsibility for the accuracy, completeness, or usefulness of any information, apparatus, product, or process disclosed, or represents that its use would not infringe privately owned rights. Reference herein to any specific, commercial product, process, or service by trade name, trademark, manufacturer, or otherwise does not nexessatily constitute or imply its endorsement, recontmendation, or favoring by the United States Goverriment or any agency thereof. The views and opinions of authurs expressed herein do not necessarily state or refloct those of the United States Government or any agency thereor.

\section{U.S. DOE Patent Clearance is Not Required Pricr to the Publication of This Document}


TABLE OF CONTENTS

\section{Page}

AUB O

. 120

LIST OF TABLES

iii

LIST OF FIGURES

iii

BACKGROUND

1

ACCOMPLISHMENTS

2

RESULTS

2

Thermal Drying

4

Microwave Drying

6

Chemical Drying .

8

Miscellaneous

8 


\section{LIST OF TABLES}

1. Proximate and UItimate Analysis of Eagle Butte Subbituminous Coal

2. Precision and Accuracy for Solutions of a Known Amount of Water by ${ }^{1}$ NMR

\section{LIST OF FIGURES}

1. Solid-State ${ }^{13_{C}} \mathrm{C}$ NMR Spectrum of Eagle Butte Subbituminous Cosl.

2. Trends in Particle Size Distribution Versus Grinding Times for Eagle Butte Coal

5

3. Calibration of Microwave Power Levels Using $1 \mathrm{~kg}$ Sample of Water 


\section{BACKGROUND}

The overall abjectives of this work are to conduct research that will provide the basis for an improved liquefaction process, and to facilitate our understanding of those processes that occur when coals are initially dissolved. Changes in coal structure that occur during coal drying and steam pretreatments will be measured in order to determine what effect water has on retrograde/condensation reactions, and to determine the mechanism by which water enhances coal reactivity toward liquefaction. Different methods for coal drying will be investigated to determine if drying can be accomplished without destroying coal reactivity toward liquefaction, thereby making coal drying a relatively economical and efficient method for coal pretreatment. Coal drying methods will include conventional thermal drying, microwave $\mathrm{d}$. ing, and chemical drying at low temperature. State-of-the-art solidstate nuclear magnetic resonance (NMR) techniques using combined rotation and multiple pulse spectroscopy (CRAMPS) and cross polarization with magic-angle spinning (CP/MAS) will be employed: (1) to measures changes in coal structure brought about by the different methods of drying and by low temperature oxidation, and (2) to obtain direct measurements of changes in the aromatic hydrogen-tocarbon ratio of the solid/semisolid material formed or remaining during pretreatment and the initial stages of liquefaction. The aromatic hydrogen-tocarbon ratios are difficult, if not impossible, to measure without the use of solid. state JMR, and as a result this ratio will be used to monitor the retrograde/condensation reactions that take place during coal liquefaction in the presence and absence of ateam and various inert gases. 


\section{ACCOMPLISHMENTS}

An Environmental Assessment Questionnaire was filled out and submitted to DOE to enable DOE to satisfy it's requirements under the National Environmental Policy Act of 1969. Because of the extremely low levels of any environmentally hazardous wastes that might be generated during the project, WRI had requested a categorical exclusion under NEPA. DOE notified WRI on May 27,1992 that all NEPA requirements have been satisfied. 'Therefore, work on the project began on June 1, 1992, and this quarterly report describes work performed since that date.

\section{RESULTS}

The objectives for this quarterly report period were to begin coal drying experiments using thermal, microwave, and chemical methods. The initial coal drying experiments are being conducted on an Eagle Butte subbituminous coal from the Powder River Basin near Gillette, Wyoming. Proximate and ultimate analyses

are reported in Table 1. A cross polarization, magic-angle spinning (CP/MAS) ${ }^{13} \mathrm{C}$ NMR spectrum of the Eagle Butte coal is shown in Figure 1. The band between 0 and $100 \mathrm{ppm}$ is associated with aliphatic carbon moieties. The band between 100 and $160 \mathrm{ppm}$ is due to aromatic carbon structures, and the small bands at $\sim 180$ and $205 \mathrm{ppm}$ are due to carbons in carboxylate and carbonyl structures, respectively. The spectrum is typical of subbituminous coals. 


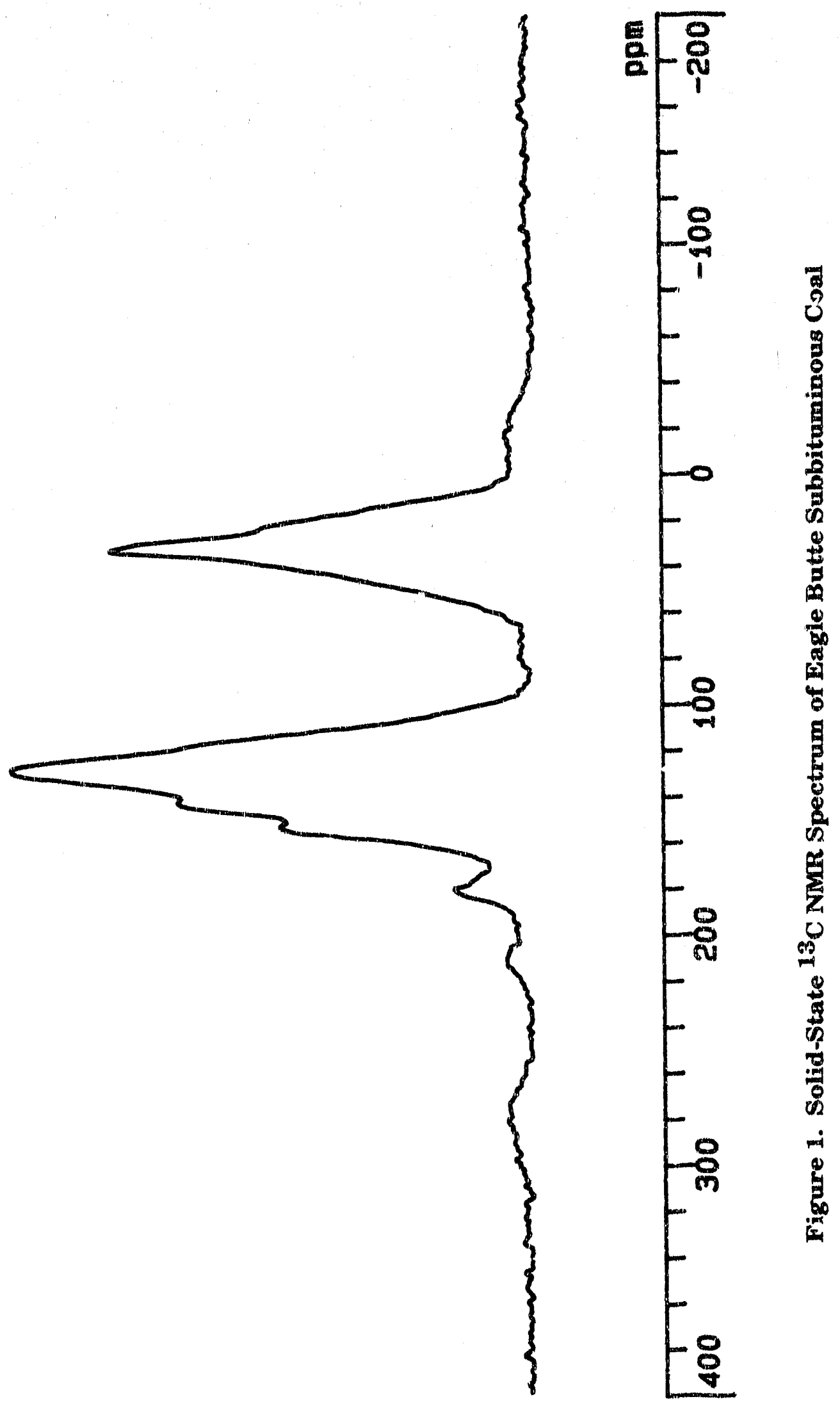


Table 1. Proximate and Ultimate Analysis of Eagle Butte Subbituminous Coal

\begin{tabular}{lclc}
\hline Proximate Analysis & & \multicolumn{2}{l}{ Ultimate Analysis } \\
Volatile Matter & 30.9 & Carbon & 67.4 \\
Fixed Carbon & 35.2 & Hydrogen & 5.1 \\
Ash & 4.7 & Nitrogen & 0.9 \\
Moisture (as rec'd) & 29.2 & Sulfur & 0.6 \\
Heating Value (Btu/lb) & 8,470 & Oxygen & 19.4 \\
& & Ash & 6.6 \\
\hline
\end{tabular}

\section{Thermal Drying}

The thermal drying efforts for the quarter consisted mainly of developing grinding and screening proceedures for the drying experiments, and setting up a thermal drying system. A small laboratory grinding mill was purchased and used to reduce the coal samples from $-1 / 8 \mathrm{in}$. bulk sample to the smaller size ranges needed for the drying tests. The reproducibility and trends in particle size distributions produced for different grinding times are shown in Figure 2.

Thermal drying of the Eagle Butte coal was monitored in a large oven that had been used for years at W RI for coal drying. The results of our tests show that the coal samples in this oven do not attain $105^{\circ} \mathrm{C}$ in the first hour of heating, and that significant weight loss is still occurring after one hour in the oven. Presently, we are testing a small, controlled-temperature furnace to whether more reasonable heating rates and more consistent weight losses can be achieved. 


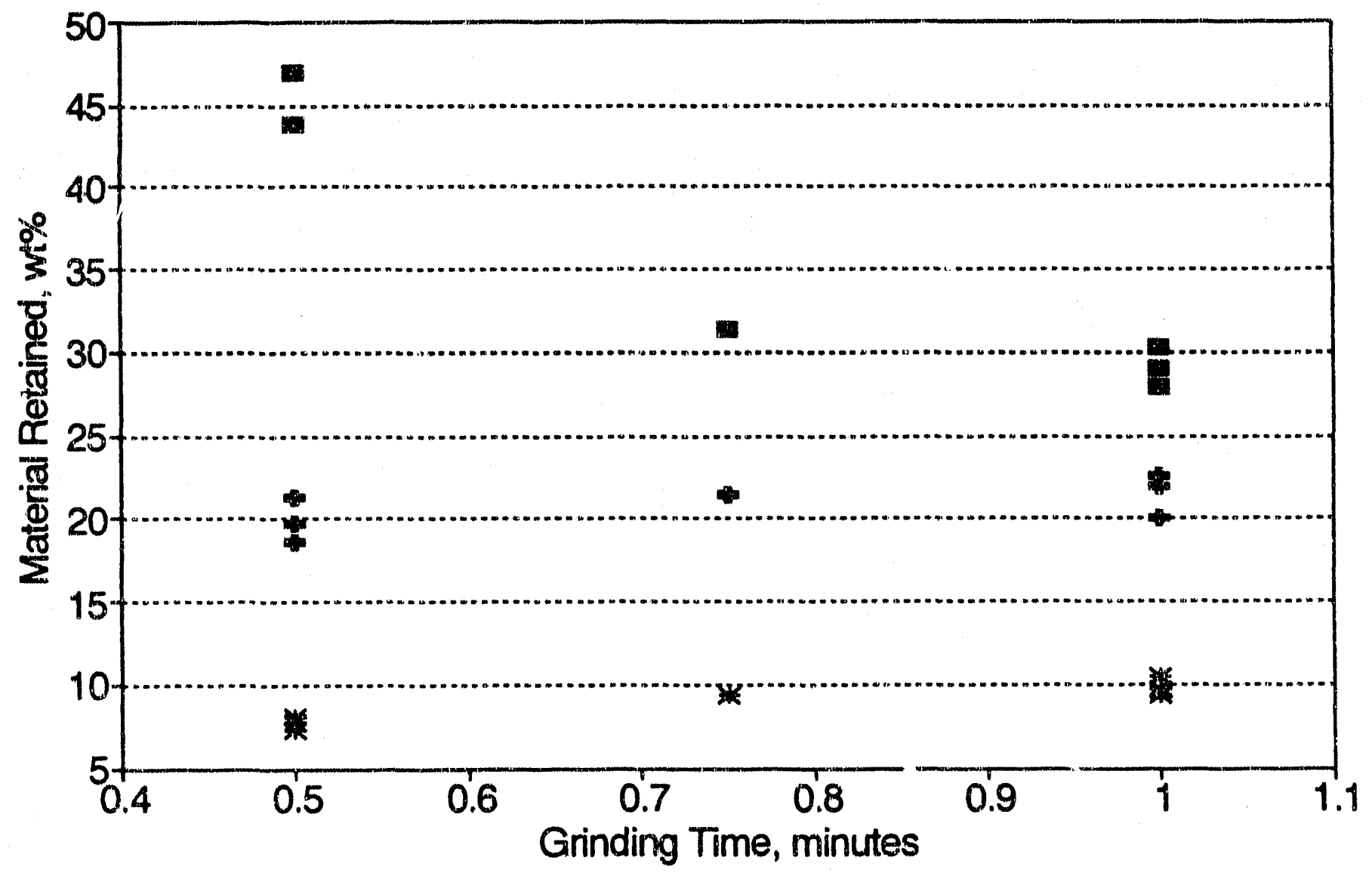

Figure 2. Trends in Particle Size Distribution Versus Grinding Times for Eagle Butte Coal 


\section{Microwave Drying}

Microwave drying experiments using Eagle Butte subbituminous coal are being conducted in a CEM model MDS 81-D laboratory microwave oven, that is equipped with facilities to introduce different gaseous environments. The microwave was calibrated at $10 \%$ power intervals using a $1-\mathrm{kg}$ sample of water (Figure 3 ). The data for the two calibration s eries show good repeatability although there is a deviation from the plot at the higher power settings. This deviation should not affect the microwave coal drying tests which will be conducted at lower power settings.

Temperature measurements of the coal as a function of microwave drying times have been a problem. Currently, 2-g samples of coal are placed in a microwave digestion sample holder that was modified to accommodate the sample. This configuration was chosen because the same sample can also be placed in the thermal drying unit to obtain moisture determinations for calibrating the microwave unit. After a given period of drying at a given microwave power level, the sample is removed and a fast-response thermocouple is placed in the coal bed to measure the temperature. Preliminary measurements indicate that there is a significant variation in the coal bed temperature from the bottom to the top of the bed. The higher temperature at the top of the bed is attributed to additional heating of the coal by superheated water escaping the coal. A new arrangement that stirs the coal during the microwave drying is being investigate and will be reported on next quarter. 


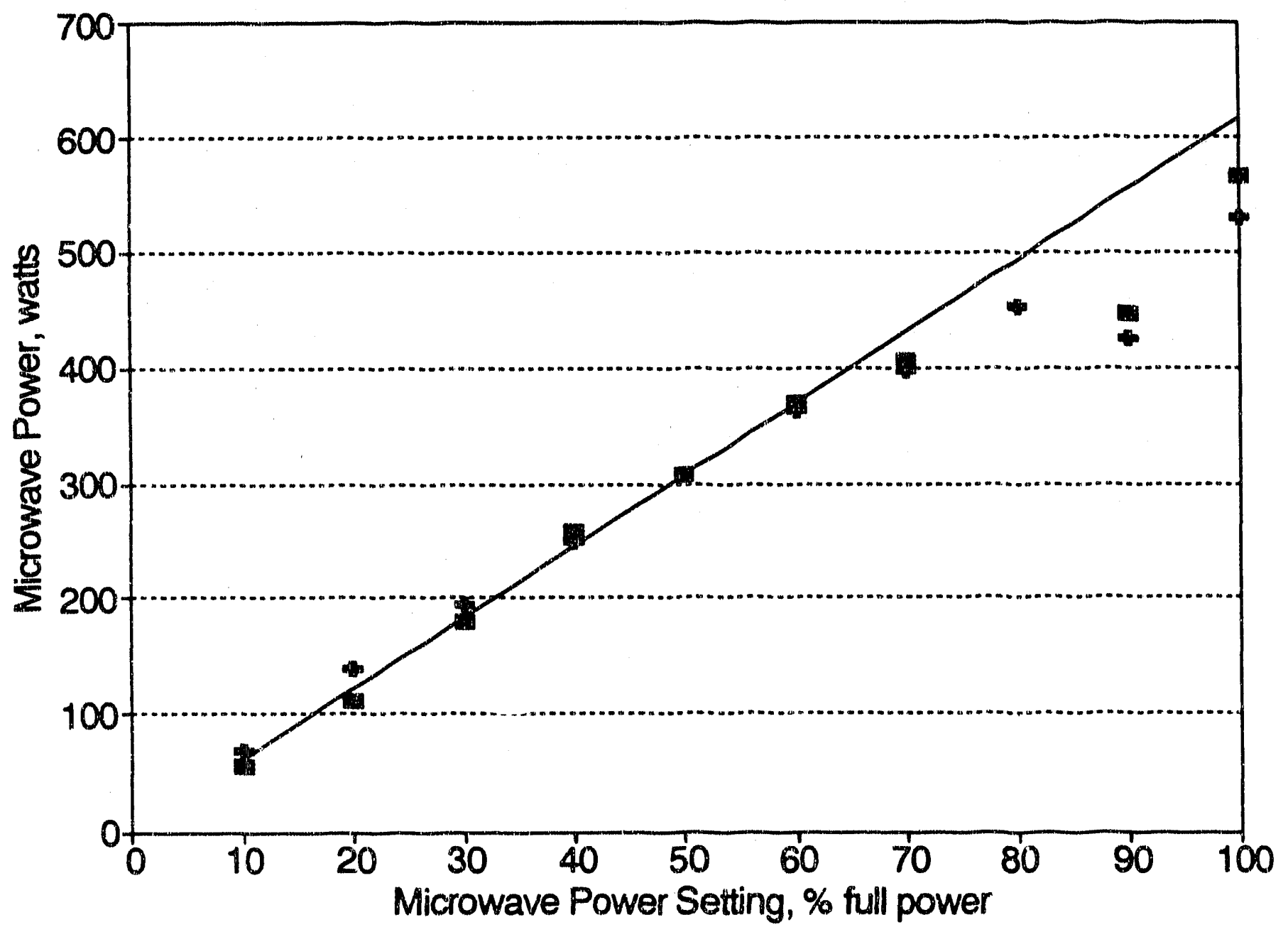

Figure 3. Calibration of Microwave Power Levels Using $1 \mathrm{~kg}$ Sample of Water 


\section{Chemical Drying}

Chemical drying experiments were conducted on Eagle Butte coal using 2,2dimethoxypropane as a drying agent. This chemical reacts with the water in coal to form acetone and methanol, both of which are readily determined by liquid-state NMR ${ }^{1} \mathrm{H}$ NMR measurements. The reaction is catalyzed by the addition of a small amount $(2 \mathrm{~mL})$ of $0.2 \mathrm{~N}$ methane sulfonic acid in methanol.

Initial work has concentrated on developing the methodology for moisture determinations in coal using the chemical drying agent. Solutions of known amounts of water $(0.0,0.05,0.10,0.20$, and $0.30 \mathrm{~g})$ were separately added to solutions of acid in methanol. The solutions were allowed to stand for about $1.5 \mathrm{hrs}$ to allow for complete reaction bfore analysis. Three separate experiments were conducted using solutions of known amounts of water to determine the precision and accuracy of the method (Table 2 ). The average relative error was $< \pm 3 \%$, and the absolute error was better than $0.005 \mathrm{~g}$ for all solutions. The percentage recovery was $100 \pm 3 \%$ over the concentration range of 0.0 to $0.3 \mathrm{~g}$ of water.

\section{Miscellaneous}

Several capital equipment items were acquired for the project. These are: a Wavetek sweep generator and oscilloscope for tuning the NMR probes, a bench top spinning module for testing sample spinning prior to insertion into the NMR probe, an analytical mill for coal preparation, and an analytical balance. 


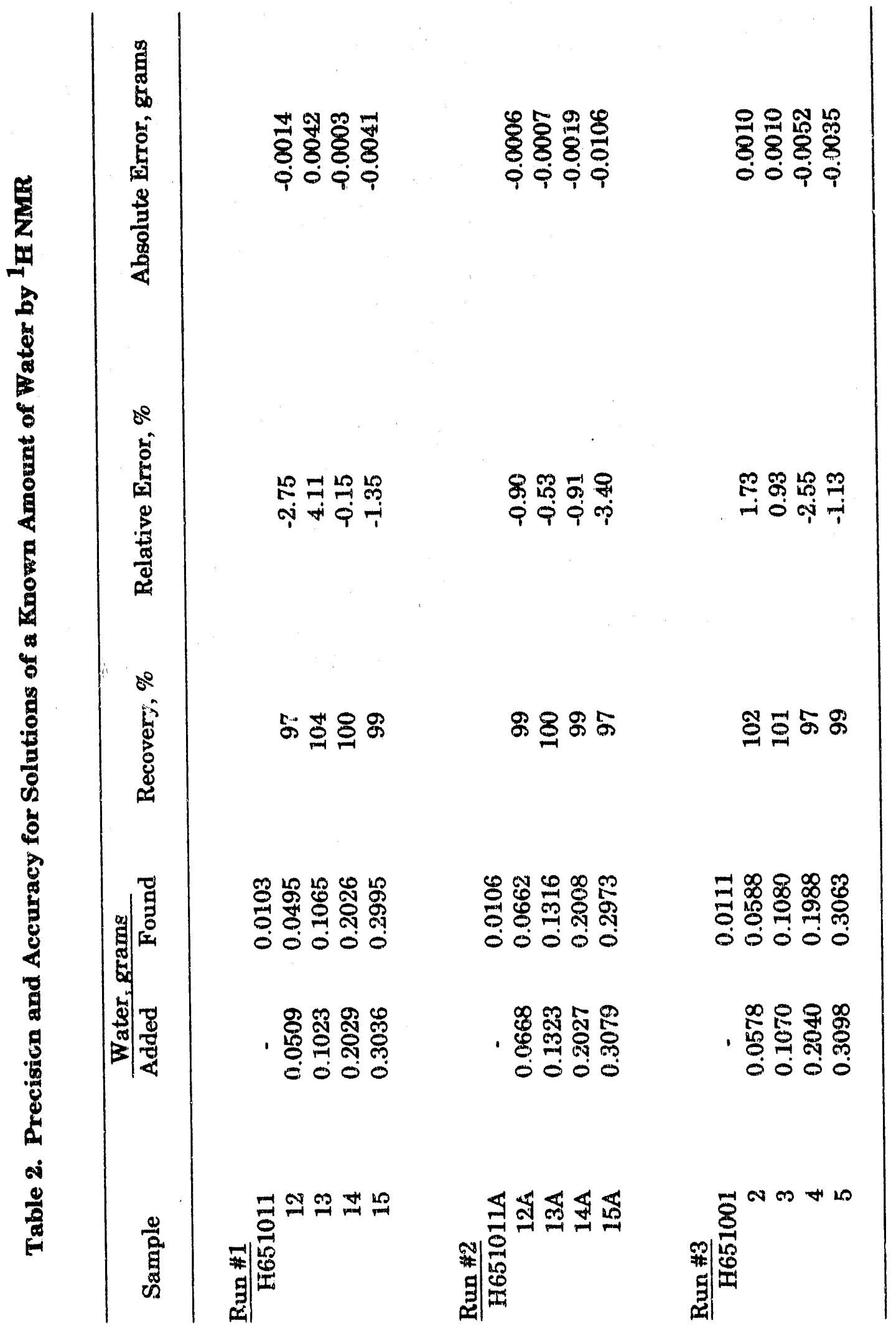


WRI also submitted a request to acquire "Borgialli" microreactor from the Wilsonville Two-Stage Advanced Coal Liquefaction Reaearch Favility. If acquired, this reactor will be used for some of the liquefaction experiments on tha dried coals. Mr. Norm Stewart, ERRI, was helpful in putting WRI in contact with the proper people at Wilsonville to pursue the ncquisition of the reactor. The present statur is that Southern Clean Fuels will put the reactor and accessories up for bid, at which time WRI will have the opportunity to tender a bid. 

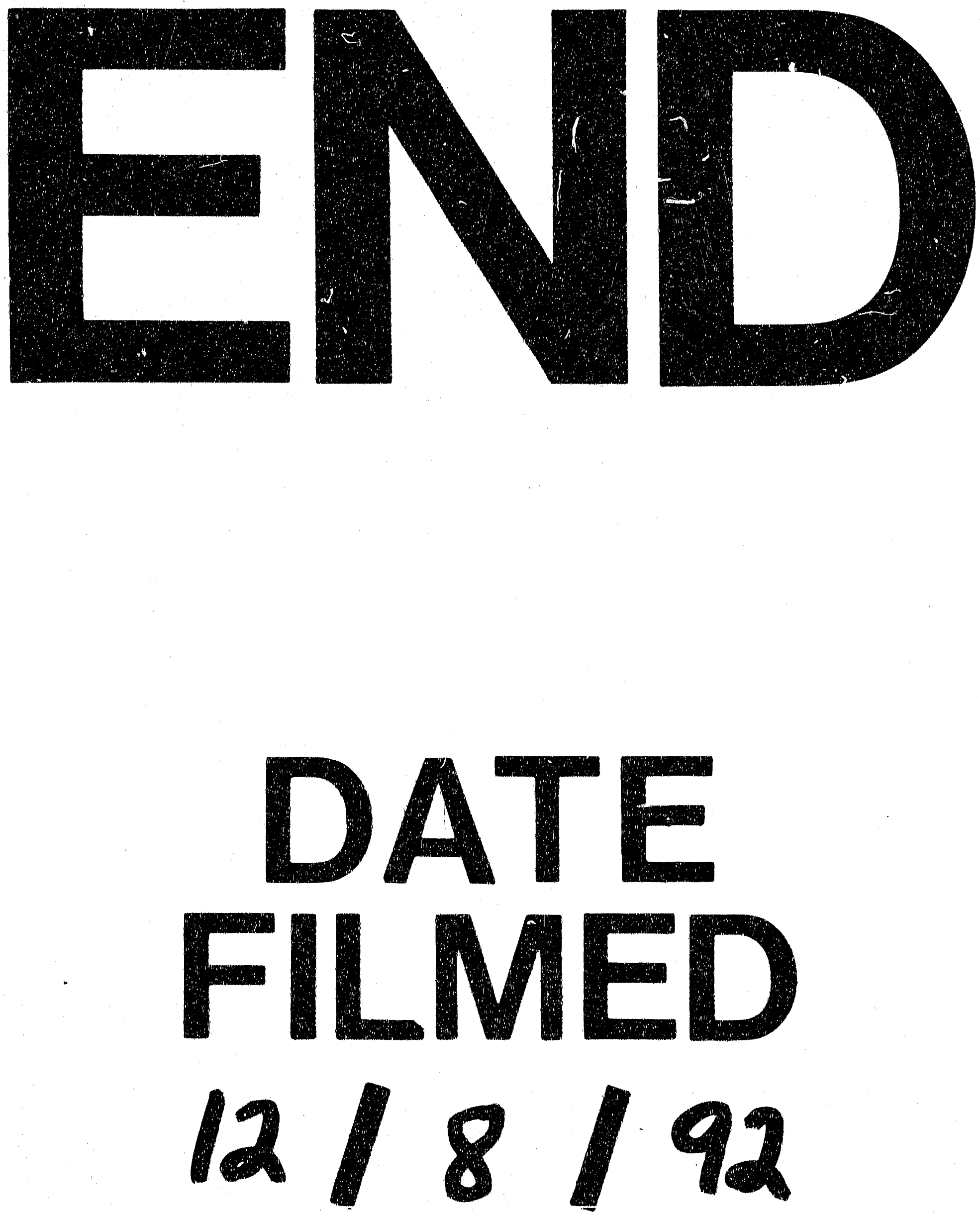
$\vdots$ 